
Research Square
Preprints are preliminary reports that have not undergone peer review.
They should not be considered conclusive, used to inform clinical practice,
or referenced by the media as validated information.

\title{
GHG displacement factors of harvested wood products: the myth of substitution
}

\section{Philippe LETURCQ ( $\nabla$ phleturcq@hotmail.fr)}

\section{Research}

Keywords: Forest carbon, Harvested wood products, Carbon accounting, Carbon neutrality, Sequestration parity, Energy and material substitution, Displacement factors, Climate change mitigation

Posted Date: June 11th, 2020

DOl: https://doi.org/10.21203/rs.3.rs-26980/v2

License: (c) (1) This work is licensed under a Creative Commons Attribution 4.0 International License.

Read Full License

Version of Record: A version of this preprint was published at Scientific Reports on November 27th, 2020. See the published version at https://doi.org/10.1038/s41598-020-77527-8. 


\title{
GHG displacement factors of harvested wood products: the myth of substitution
}

\author{
Philippe Leturcq \\ University of Toulouse
}

Correspondence: phleturcq@hotmail.fr

Author information is available at the end of the article

\begin{abstract}
Background: A currently held idea is that substituting wood for fossil fuels and energy intensive materials reduces greenhouse gas emissions. This idea is supported by the values that are usually attributed to the displacement factors; these factors normalise the emission reduction to the wood carbon mass (typically, $0.5 \mathrm{tC} / \mathrm{tC}$ for fossil fuel substitution, $2 \mathrm{tC} / \mathrm{tC}$ for building material substitution). These values are based on the "carbon neutrality" assumption of harvested wood, which is claimed valid as long as forests are sustainably managed, but holds true in static conditions only. Harvesting disturbs forest growth and wood carbon storage for a long time. Therefore, the carbon footprint of harvested wood and related displacement factors must be assessed as time-dependant quantities, and the effect of substitutions should be appreciated relatively to specific time horizons. In this study, the meaning, values and use of the displacement factors are reconsidered according to this new line of thinking.
\end{abstract}

Results: When taking into account the forest carbon dynamics, the presumed values of the displacement factors under the carbon neutrality assumption are achieved only in steady-state conditions, a very long time after harvest. Shortly after harvest, and even for time horizons comparable with climatic deadlines, the transient values of these factors appear much less than the steady-state values, and may even be negative. This is especially the case for the substitution of wood for fossil fuels which first increases the carbon emission for the same energy released. An additional weakness of the ordinary concept of displacement lies in possible misevaluations of 
carbon benefits from substitution, especially when large sectors of wood products are concerned or when the market conditions are disregarded. Corrective measures are proposed for this.

Conclusions: The use of inadequate constant values of displacement factors under the carbon neutrality assumption, and the supposition that wood substitution for other fuels or materials is always possible and effective, leads to overestimations of carbon benefits. These overestimations erroneously incite the increase in harvesting and wood utilisation, which may be counter-productive for climate change mitigation objectives, especially when wood is used as a fuel.

Keywords: Forest carbon, Harvested wood products, Carbon accounting, Carbon neutrality, Sequestration parity, Energy and material substitution, Displacement factors, Climate change mitigation.

\section{Background}

Wood as a substitute for carbon intensive fuels or materials is generally thought of as efficiently contributing to the overall reduction of greenhouse gas (GHG) emissions [e.g. 1-8]. This opinion is highly questionable for two reasons.

Firstly, these substitutions have to be justified on a case-by-case basis by comparing the carbon footprints of wood and non-wood products that are considered to be functionally interchangeable. However, the carbon footprint of harvested wood products (HWP) is not so easy to assess as it largely depends on that of the forest domain from which the woody material originates [9-11]. Deficiencies in the forest carbon dynamic description may affect the evaluation of carbon footprints of harvested wood products and, consequently, that of the climate mitigation effect of their substitution to non-wood products [12-15]. In particular, the assertion of carbon neutrality, which presupposes the invariability of the forest carbon stock, leads to unrealistic estimates of the carbon footprints of harvested wood products $[16,17]$. 
Secondly, when assessing the climate change mitigation potential of forest and wood use at a local, regional, national or global scale, a current practice is to apply "displacement factors" (DFs) to large segments of the HWP production [e.g. 18-24]. "Displacement factors" (or "substitution coefficients") are averaged differences between the absolute value $\left|f_{n w}\right|$ of the carbon footprint of non-wood products and that $\left|f_{w}\right|$ of functionally equivalent wood products, normalised for convenience to the carbon mass content $C_{w}$ of the wood products [25]:

$$
D F=\left(\left|f_{n w}\right|-\left|f_{w}\right|\right) / C_{w}
$$

Most studies using this approach conclude that large GHG emission reductions may be obtained from the substitution of wood for materials such as concrete, steel or aluminum, as well as from the substitution of wood for fossil fuels. However, these expected reductions are misestimated in many cases since the above mentioned uncertainties relative to the carbon footprints of HWP directly affect the displacement factor values. In addition, by applying displacement factors to a large spectrum of wood products, a serious risk exists that all envisaged substitutions may be not effective or even possible [26-28].

The danger is that overestimated GHG emission reductions by substitution are an incentive to increasing wood harvesting, which could be counter-productive for climate change mitigation objectives and detrimental for forest ecosystems. Effects of substitution, as they are commonly evaluated, do not seem to correspond to reality and a back to basics is necessary.

In this study, some misconceptions about the HWP carbon footprint assessment and substitution effectiveness in reducing overall GHG emissions are pointed out and explained. Emphasis is placed on two methodological keys: (i) the essentials of the carbon exchanges between forest, wood products and atmosphere, (ii) the time dependence of the carbon footprint of harvested wood and, consequently, that of the displacement factors. Implications on (iii) wood utilisation as a fuel, (iv) 
wood utilisation as a material, and ( $v$ ) the conditions under which the planned substitutions may become effective, are then presented and discussed.

\section{Methods}

\section{Carbon exchanges between the "forest-wood system" and the atmosphere}

Figure 1 is a schematic description of carbon flux exchanges between the forest, HWP and the atmosphere. The forest perimeter considered is arbitrary: it can be a single stand or the forest of an entire country. $G$ represents the net primary production (NPP) of biomass. $E 1$ is the emission due to the decomposition of dead organic matter and $R$ is the amount of harvested wood. All these fluxes can be expressed in terms of carbon mass on an annual basis. $E 2$ is the post-harvest carbon emission originating from the use of wood as a fuel and/or from the combustion or decomposition of woody residues and discarded products. $S$ indicates the emission variation resulting from selected substitutions of wood fuel or manufactured wood products for more GHG intensive non-wood products. An additional emission E3 includes the external emissions that are linked to forest management, harvest, transport, industry processes, etc. Two carbon stocks must be considered: one in the forest biomass, the other in the wood products. The variations in these two stocks depend on the related carbon fluxes according to the mass conservation principle.

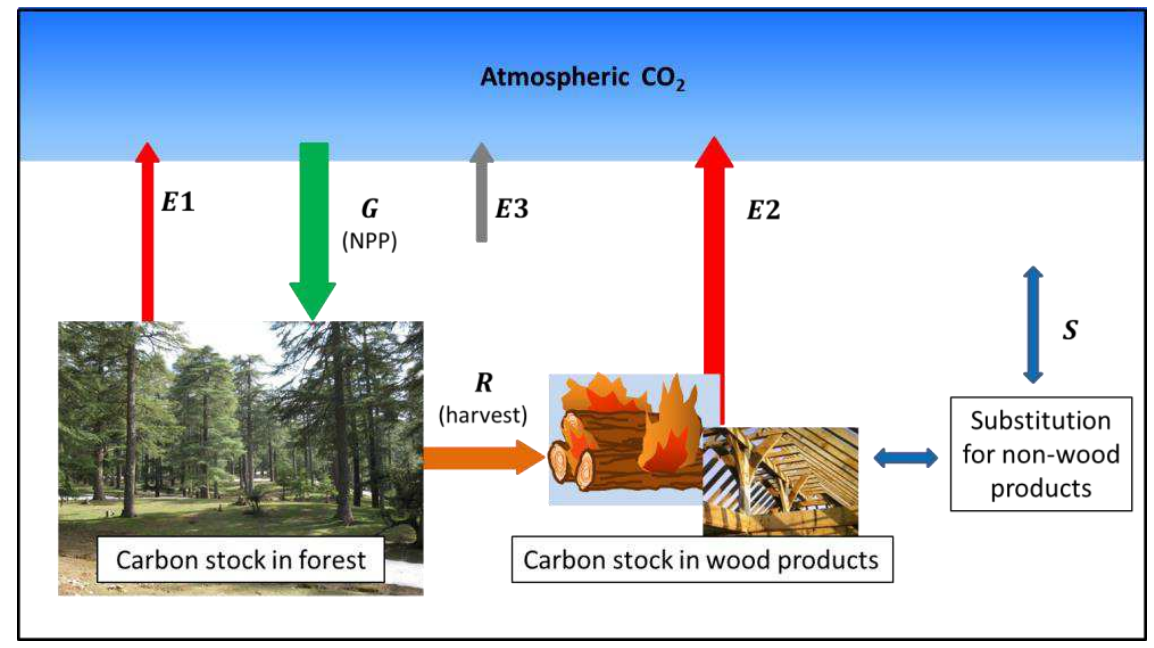


Fig. 1 Carbon flux exchanges between forest, wood products and atmosphere

(G: Net primary production; E1: decomposition of dead organic matter; R: harvested wood;

E2: combustion or decomposition of harvested wood; E3: external emissions; S: substitution effect)

Leaving aside the additional $E 3$ emission for the moment, the net primary production $G$ may be greater or less than the sum of $E 1$ and $E 2$ emissions. In the first case, the forest and the woodproduct sector behave as a carbon sink for the atmosphere, allowing direct climate change mitigation. Conversely, in the second case, the "forest-wood system" acts as a carbon source, which should be avoided. There is "carbon neutrality" if $G$ equals the sum $E 1+E 2$, which can only be seen as a special case.

In another way, harvested wood can be used to replace other fuels or other materials. Such a substitution can be favourable or unfavourable, depending on whether the life cycle of the displaced product is more or less emissive than that of the wood product.

Therefore, two mitigation strategies are possible a priori: the one is direct and consists in reinforcing the carbon sink; the other is indirect and lies in an increase in wood harvesting with a view to favourable substitutions. These two strategies are opposite, since increasing the harvest cannot be done without weakening the forest carbon sink. Thus, a comparison of exact carbon footprints of wood and non-wood equivalent products is needed to arbitrate. While the carbon footprint of non-wood products is generally easy to achieve as a single well-defined quantity through a conventional life cycle assessment, that of wood products presents the particularity to be a timedependent measure from cradle (the forest) to grave (combustion or decomposition).

Since the forest-wood system exchanges carbon only with the atmosphere, the carbon footprint of any action is represented, at every moment, by the consecutive change in the carbon stock of the system, in comparison with the carbon stock which would be observed in absence of this action (baseline). Referring to fig.1, the "intrinsic" carbon footprint of wood harvest and utilization cumulates the change in the forest carbon stock due to harvesting and that in the carbon stock of the 
products originating from the harvest. The additional (or "extrinsic") E3 emission that is external to the forest-wood system can be assessed separately and added ultimately to the intrinsic carbon footprint.

The above mentioned carbon neutrality supposes that there is no variation in the forest carbon stock and can therefore be observed only in the steady-state of the forest-wood system. However, this "neutrality" is often abusively invoked to justify increases in the amount of wood harvested on the pretext that the substitution of wood for other fuels or other materials would "avoid" the emissions linked to their use. It is important to highlight that an increase in harvests implies a change in the forest carbon stock, thereby suppressing neutrality if it previously prevailed. It is well known that the average cost and marginal (or incremental) cost of a production are different. The same is true for carbon footprints. Even if the forest has been managed for a long time at constant stock, the intrinsic carbon footprint of an additional harvested wood cannot be "zero" and must be determined from the subsequent changes in carbon stock. Many forest, environmental and energy policies, particularly in Europe, are wrong in this regard as pointed out by several authors [e.g. 29-33].

\section{Carbon footprint of wood harvest}

Figure 2 illustrates the consequence of harvest on the forest carbon stock variation relative to that which would be observed without harvest. The simple case considered is a single harvest with a carbon content $Q_{h}$ operated in a forest containing a much larger stock. There is no loss of generality as far as the effects of sequential harvests are additive. Whatever the prior evolution of the forest carbon stock, increasing, decreasing or constancy, the consequence of harvest is the same. Three main processes act together. (a) The removal of $Q_{h}$ is a step change in the forest carbon stock. (b) Harvest residues are generally not removed from the forest. These residues that are principally worthless branches and tops, stumps, coarse roots and other woody debris, have a carbon content $Q_{r}(t)$ which may initially amount to as much as $50 \%$ of $Q_{h}$. The carbon content $Q_{r}(t)$ continues to be a part of the forest stock but decreases progressively in time owing to decomposition of the 
residues. The decay has an exponential appearance following an approximate first order dynamic with a time constant $\tau_{d}$. (c) The forest regenerates, implying a positive change in carbon stock. This curve represents the difference between the increment of the actual carbon stock and that which would be observed in the absence of harvest (baseline). It is nearly exponentially shaped with a dominant time-constant $\tau$. This time-constant can be viewed as the mean residence time of carbon in forest biomass in the absence of harvest and serves as the time unit for the horizontal axis in fig. 2 . Values of $\tau$ may range from decades up to several centuries for semi-natural or natural forests of long-lived tree species. In fig. 2 , the decomposition time constant of harvest residues $\tau_{d}$ is presumed smaller than $\tau$.

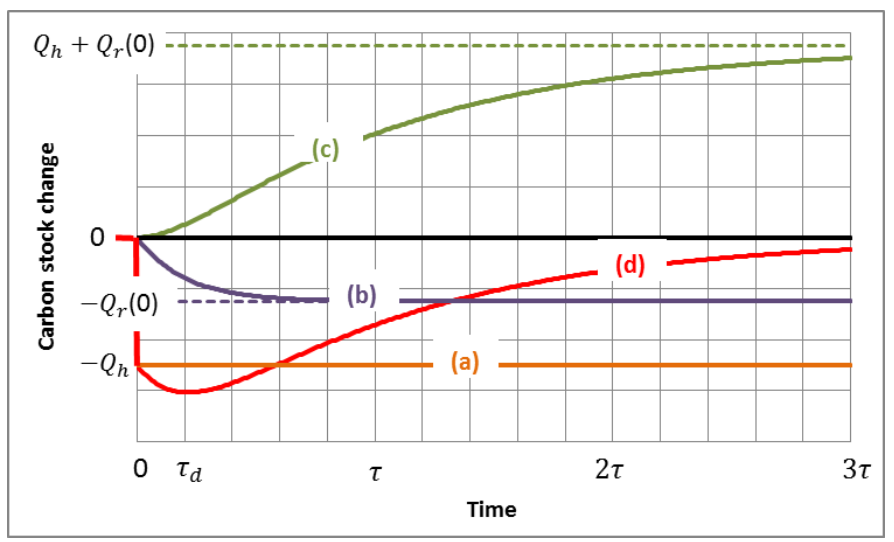

Fig. 2 Main components of the forest carbon stock change (d) due to harvesting

(a): carbon content of the harvested wood (b): decomposition of harvest residues (c): forest regeneration

The total carbon stock change, shown as (d) in fig.2, represents the intrinsic carbon footprint of harvesting as regards the forest, leaving aside the related part of the additional $E 3$ emission. Under conditions that tree species, soil fertility, climate and forestry management remain unchanged, the same final equilibrium state of the forest can be expected to be reached whether or not harvest occurs, or, in other terms, the post-harvest evolution of the forest converges to that without harvest (base-line). Thus, it can be inferred that the carbon footprint of harvesting tends towards zero long 
afterwards, as it is assumed in fig.2. The implicit sign convention is (-) for carbon emission, (+) for carbon capture.

This simple description of the carbon dynamics holds as long as the net primary productivity of the forest is not significantly affected by the harvest. This is the case as far as the continuity of the canopy is not severely disturbed, in the case of a light thinning for instance [34]. Otherwise, the lack of carbon capture until the forest cover is restored must be taken into account. The general pattern of the change in carbon stock is then the same as (d) but its amplitude is increased and the extremum occurs later in time.

As evidenced by fig. 2, the intrinsic carbon footprint of harvesting, which coincides with the total carbon stock change (d), is formed over time and cannot be summed up in a single figure as is the case for actions, activities, productions in which the emission is almost instantaneous and where there is no carbon capture. Taking into account the usual values of the main time constant $\tau$, the time axis scale is graduated in decades or even centuries and therefore may go far beyond the deadlines asserted by the United Nations Climate Change Conferences (e.g. 2050 and 2100). Hence the need to set time horizons compatible with these deadlines, such as what is done when comparing the global warming potentials (GWP) of different greenhouse gases.

\section{Results and discussions}

\section{Carbon footprint of wood utilisation as a fuel}

Line (d) in fig. 2 also represents the intrinsic carbon footprint of the forest-wood system for an immediate utilization of the harvested wood as a fuel, since no carbon stock change occurs in the wood-product sector. Soon after harvest (time $t$ much less than $\tau_{d}$ and $\tau$ ), the absolute value of the carbon footprint is not perceptibly different from the carbon content $Q_{h}$ of the wood fuel. This justifies a carbon accounting of common sense (but short-sighted) which considers that the wood that is burnt simply returns its carbon to the atmosphere. For times $t$ less than $\tau$ but more than $\tau_{d}$ $\left(\tau_{d}\right.$ is generally much less than $\tau$ ), the carbon of the harvest residues is added and, as far as the 
forest carbon stock recovery remains negligible, the absolute value of the footprint approaches the sum $Q_{h}+Q_{r}(0)$. Afterwards, the variation of the carbon footprint is dictated by the gradual recovery of the carbon mass $Q_{h}+Q_{r}(0)$ as the forest regenerates. Finally, for $t \rightarrow \infty$, the carbon footprint tends towards zero. This "carbon neutrality" long after harvest is interesting from a theoretical point of view, but a non-zero carbon footprint is evident for durations of a few units of $\tau$, that is to say from several decades to many centuries.

When comparing wood fuel to fossil fuels as regards climatic impacts, the pertinent physical characteristic is the $\mathrm{CO}_{2}$ emission factor, that is the amount of carbon (or carbon dioxide) emitted per unit of released energy. Values of this intrinsic emission factor taken from a standard source [35] are shown in table I (second column) for representative fuels. The combustion emission of wood is clearly higher than that of other fuels.

Table 1 -Typical emission factors for representative fuels, and displacement factors

\begin{tabular}{|l|c|c|c|c|}
\hline \multicolumn{1}{|c|}{ Fuel } & $\begin{array}{c}\text { Intrinsic emission } \\
\text { factor } \\
\left(\mathrm{kgCO}_{2} / \mathrm{GJ}\right)\end{array}$ & $\begin{array}{c}\text { Effective emission } \\
\text { factor } \\
\left(\mathrm{kgCO}{ }_{2} \mathrm{eq} / \mathrm{GJ}\right)\end{array}$ & $\begin{array}{c}\text { Displacement factor } \\
\text { at combustion } \\
(\mathrm{tC} / \mathrm{tC})\end{array}$ & $\begin{array}{c}\text { Displacement factor } \\
\text { under wood carbon } \\
\text { neutrality }(\mathrm{tC} / \mathrm{tC})\end{array}$ \\
\hline Wood & 112 & 117 & - & - \\
\hline Anthracite & 98 & 103 & $-0,12$ & $+0,87$ \\
\hline Heating oil & 73 & 85 & $-0,29$ & $+0,71$ \\
\hline Natural gas & 56 & 67 & $-0,45$ & $+0,55$ \\
\hline
\end{tabular}

Displacement factors are dimensionless $\left(\mathrm{tC} / \mathrm{tC}\right.$ or $\left.\mathrm{kgCO}_{2} / \mathrm{kgCO}_{2}\right)$. The values of displacement factors are calculated from the effective values of emission factors, setting $5 \mathrm{kgCO}_{2} \mathrm{eq} / \mathrm{GJ}(E 3)$ in the case of wood under the carbon neutrality assumption

Therefore, as long as extrinsic emissions ( $E 3$ for wood) related to extraction, transportation, refining and distribution of fuels can be ignored or neglected, the carbon footprint of the use of a fossil fuel giving the same energy as that of harvested wood may be represented in fig. 3a by a step function (e). The step amplitude is proportional to $Q_{h}$; the proportionality coefficient is the ratio of the emission factor of the fossil fuel to that of wood and thereby this amplitude is smaller than $Q_{h}$. 
The use of wood as a fuel then appears to be intrinsically more emissive than that of other fuels for time horizons nearer than the time $T$ corresponding to the intersection of the lines that represent the carbon footprints in fig. 3. The carbon footprint of using wood, on the other hand, is less (in absolute value) than that of the fossil fuel beyond $T$. Time $T$ corresponds to the "time to sequestration parity" according to the terminology of Mitchell et al. [10].

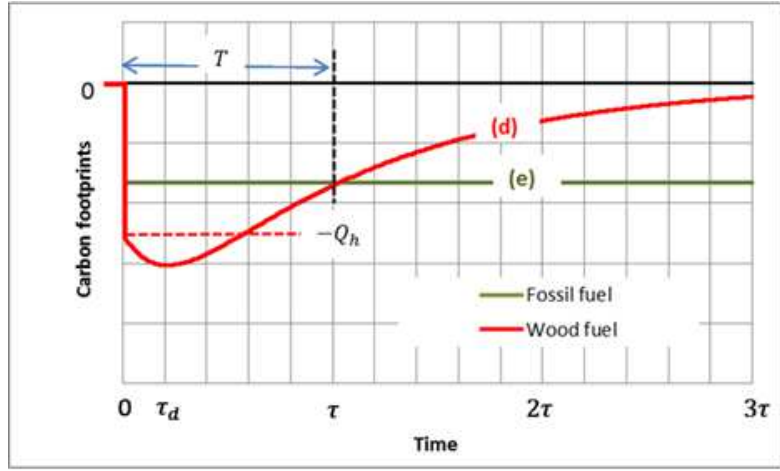

(a) Intrinsic carbon footprints

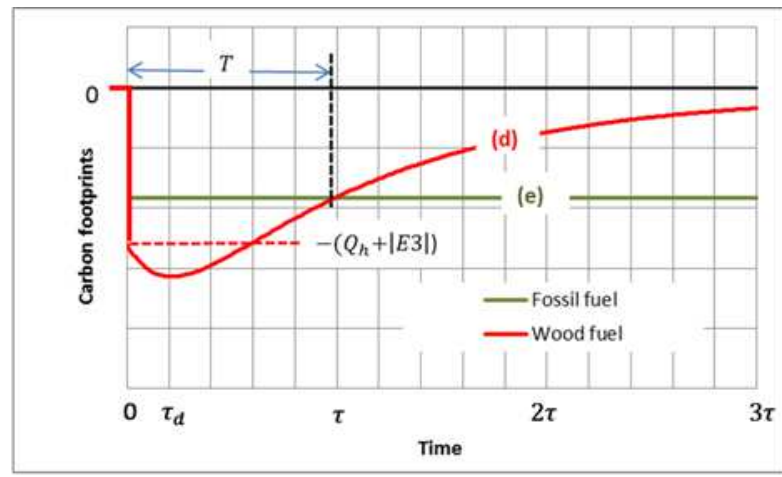

(b) Extrinsic emissions taken into account

Fig. 3 Comparison of the carbon footprints of wood and fossil fuels for the same energy released

Some complexity is added when one takes into account extrinsic emissions ( $E 3$ for wood) and also small quantities of $\mathrm{GHG}$ other than the $\mathrm{CO}_{2}$ produced in combustion. Typical values of the resulting effective emission factor in terms of $\mathrm{CO}_{2}$ equivalent are given in the third column of table I [36]. Fig. 3a must then be slightly modified (fig. 3b).

The time $T$ to sequestration parity depends mainly on the time constant $\tau$ of the forest carbon dynamics and on the relative emission factors of wood and fossil fuels. Under the conditions of the explanatory figure 2 (net primary productivity of the forest unaffected by felling; volume of harvest residues amounting to $50 \%$ of that of harvested wood; $\left.\tau_{d} \approx \tau / 5\right)$, the values of $T$ are approximately $0.7 \tau$ for a wood-for-coal substitution, $1.25 \tau$ for a wood-for-gas substitution. $T$ nearly equals $\tau$ for a wood-for-oil substitution (case represented by figure 3). If the net primary production is temporarily reduced due to a significant lightening of the canopy, time $T$ may be much greater than the preceding values. This partially explains the dispersion of the published $T$ values, generally some 
decades in the case of wood-for-coal substitution but largely exceeding one century in the case of oil and natural gas [e.g. 37-39].

An inescapable fact is that replacing a fossil fuel with wood increases the combustion emissions for the same energy released [40]. It is only over time that the regeneration of the forests from which the wood is extracted makes it possible to compensate for the excess emission and thus to envisage a GHG benefit from substitution. Thus, as evidenced by fig. 3, the displacement factor that quantifies the difference between the carbon footprint of wood and that of the substituted fuel is itself timedependant. Just after combustion, displacement factors exhibit negative values, whatever the displaced fossil fuel, as shown in the fourth column of table 1. A positive value indicating a GHG benefit may be achieved only beyond the time $T$ to sequestration parity. It is only long after harvest and if the depleting effect of this harvest on the forest carbon stock evolution totally vanishes, that the wood energy may be seen as "carbon neutral". The carbon footprint of the use of wood as a fuel is then reduced to the additional $E 3$ emission. In this case, the displacement factors take the values indicated in the fifth column of table 1.

Most studies promoting wood energy refer to constant positive values of displacement factors on the grounds of a permanent "carbon neutrality" which, in fact, is only theoretically achieved a very long time after harvest. When considering fuel mixes at a regional or national scale, the displacement factor values according to this point of view spread from $0.5 \mathrm{tC} / \mathrm{tC}$ (e.g. France [18]) to $0.8 \mathrm{tC} / \mathrm{tC}$ (e.g. Finland [41]). These values are improper, leading to a large overestimation of the benefits of substituting wood for fossil fuels, assuming that such a benefit is still possible. Indeed, wood is more emissive than other fuels (except, perhaps, lignite or peat) and it is the forest which, by its own carbon dynamics, may allow compensation over time for wood combustion emission. The existence of a time $T$ to sequestration parity beyond which the GHG benefit would become perceptible thus is speculative since it depends on the future of forest growth. Finally, as coal may be advantageously displaced by oil, oil by natural gas and gas by non-carbonaceous sources of energy that are available, 
the theoretical time lapse before a GHG benefit can be expected from use of wood as a fuel will be soon an irrelevant notion.

\section{Carbon footprint of wood utilisation as a material}

If the harvested wood is fully and sustainably preserved instead of being burned, its carbon content is added to the forest stock. The carbon footprint variation then is similar to that corresponding to the case of combustion, taking into account a positive shift of amplitude $Q_{h}$ along the ordinate axis (figure 4). Leaving aside the $E 3$ emission which here also includes emissions linked to manufacturing processes, the two lines (d) and (d') in fig. 4a limit the range in which the carbon footprint falls within, according to the proportion of woody residues in the industry processes and the lifespans of the manufactured wood products. The proportion of woody residues can amount to half, or more, of the raw material and the manufactured products become residues themselves when they reach the end of their use. These residues generally release their carbon quickly through combustion or decomposition so that the carbon footprint of the wood utilisation as a material is, in most cases, closer to the lower limit (d) than the upper one $\left(d^{\prime}\right)$. Line (f) gives an example for a proportion of woody industrial residues of $50 \%$ of the raw material and an average product lifetime comparable to the time constant $\tau$.

In order for the footprint to become positive (net capture), at least temporarily, most of the harvested wood material should therefore be preserved as long as possible. Nevertheless, in all cases, the intrinsic carbon footprint should tend to zero after a long time $(t \rightarrow \infty)$, due to the limited lifespan of wood products or, when taking into account the additional emissions, the complete carbon footprint $f_{w}$ should tend to $E 3$ (fig. $4 \mathrm{~b}$ ). Thus, carbon storage in wood products generally has no direct mitigation effect on climate change, owing to the disturbance brought by harvesting to the forest carbon stock, except under special conditions. 


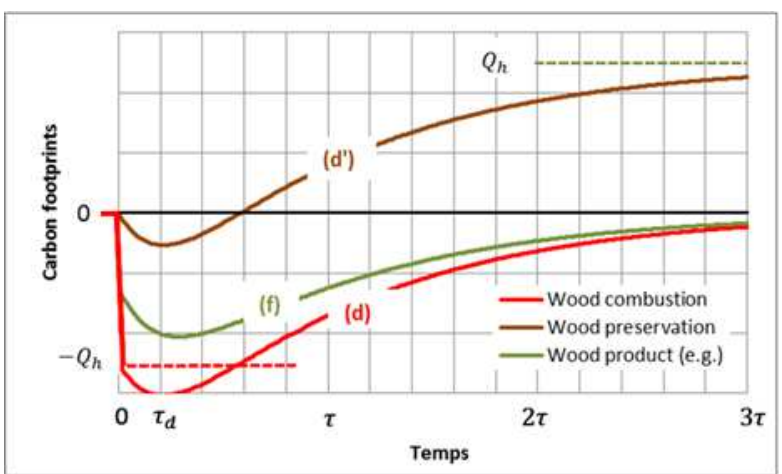

(a)

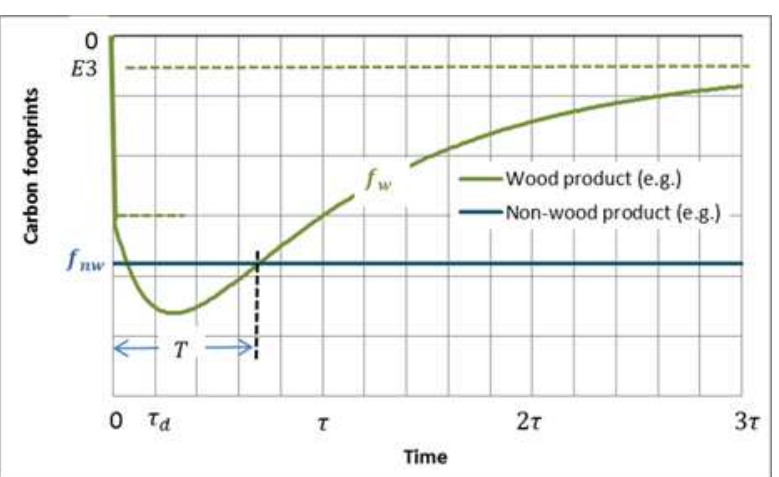

(b)

Fig. 4. Example of a carbon footprint of a wood product (a) and definition of the time to sequestration parity in the substitution for a non-wood product (b) The vertical scale unit in fig. $4 \mathrm{~b}$ is divided in two for clarity in comparison to that in fig. $4 \mathrm{a}$

The carbon footprint of substitutable non-wood products can be represented on graphs such as this of fig. $4 \mathrm{~b}$ by a horizontal line of ordinate $f_{n w}$, insofar as this footprint is fixed as soon as the products are manufactured. The time ranges for which the substitution of wood products for the non-wood products is GHG beneficial are bounded by the intersections of the two representative plots $f_{w}$ and $f_{n w}$. Thus, as for energy substitution, it is possible to define a time $T$ to sequestration parity beyond which a reduction of global emissions can be expected. If $f_{n w}$ is contained between the initial value and the extremum of the wood product footprint, there is also a short time window during which the substitution is temporarily beneficial. For higher values of $\left|f_{n w}\right|$ the substitution is permanently beneficial.

Again, as figure $4 \mathrm{~b}$ highlights, the displacement factor that quantifies the difference between carbon footprints of substitutable wood products and non-wood products is time dependent. According to definition (1), long after harvest and manufacture $(t \rightarrow \infty)$, the displacement factor tends towards a constant value $\left(\left|f_{n w}\right|-|E 3|\right) / C_{w}$. This is the value that is retained in studies that disregard changes in the forest carbon stock and refer to the assertion of carbon neutrality of wood, as explained in section 3.2. For instance, Sathre and $\mathrm{O}^{\prime}$ Connor [25] report displacement factors ranging from -2.3 to 15 tons of carbon emission reduction per ton of carbon in wood products, 
depending on specific applications in building construction, with an unweighted average value of 2.1 $\mathrm{tC} / \mathrm{tC}$. Many authors put forward comparable estimates with slight differences owing to the country and application sector concerned. Examples are weighted averages of $3.48 \mathrm{tC} / \mathrm{tC}$ and $1.36 \mathrm{tC} / \mathrm{tC}$, respectively, for construction and furniture production in China [24]; $1.5 \mathrm{tC} / \mathrm{tC}$ for overall material substitution in Germany [42]; $1.2 \mathrm{tC} / \mathrm{tC}$ for timber in France [18]; $1.0 \mathrm{tC} / \mathrm{tC}$ for sawn wood in Finland [43], etc. However, as evidenced by fig.4b, the pertinent displacement factor values may be very different when definition (1) is applied at a definite moment or on average over a certain time horizon. When taking into account the decomposition of harvest residues (up to $50 \%$ of the harvest in carbon mass), the combustion or decomposition of the manufacture residues (typically between $50 \%$ and $70 \%$ of the harvest), the carbon footprint can peak, in addition to $|E 3|$, to twice or four times the carbon mass in the wood product. Therefore, the displacement factor at the time when extremum occurs should be reduced by two or four units of $\mathrm{tC} / \mathrm{tC}$ as compared to the above mentioned estimated values. The range of negative displacement factors for which substitution increases emissions instead of reducing them is then considerably broadened. In all cases, the GHG benefits expected from material substitution are overestimated, as already inferred by some authors $[44,45]$

The conventional DF values refer to an infinite horizon time (zero intrinsic carbon footprint of harvest and wood utilisation). It should be understood that the use of constant displacement factors is not consistent with taking forest carbon dynamics into account, unless they are defined as mean values relative to a given horizon time.

\section{Applicability of the concept of substitution}

Numerous studies have highlighted energy substitution and material substitution as forest levers for climate change mitigation [e.g. 19, 46-50]. Most authors consider that substitutable wood products may truly replace homologous non-wood products and apply averaged displacement factors to more or less extensive sets of wood products. This leads to estimates of emissions that are globally 
"avoided" by substitution effects, at the scale of a region or an entire country. The amount of avoided emissions is thought of as enlarging the carbon sink of the forest-wood system. The results are an incentive for an increase in usage of wood as fuel or material and, upstream, for raising harvested wood volumes. However, these avoided emissions, already overestimated when the "carbon neutrality" of wood is invoked, generally remain largely potential. The reason can be explained as follows.

Let us consider two types of product having the same function and the same lifespan, one made of wood, the other made of another material. Let $N_{w}$ and $N_{n w}$ be the number of units annually produced of these products. The absolute value $|E|$ of the greenhouse gas emission linked to this production is:

$$
|E|=\left|f_{w}\right| N_{w}+\left|f_{n w}\right| N_{n w}
$$

where $\left|f_{w}\right|$ and $\left|f_{n w}\right|$ are the respective absolute values of the carbon footprints by units of these two types of products. If the productions $N_{w}$ and $N_{n w}$ are constant from year to year, the emission $|E|$ is itself constant and there is no reason to make one or the other production benefit from any "credit" of substitution. As specified by Sathre and O'Connor [51 p.98], "Taking a greenhouse gas "credit" for wood substitution is only valid if the application of wood is verifiably a substitution for another material. There is no additional GHG benefit in the continued use of wood products for applications where they are typically already used".

There is an increase or reduction in emission only in relation to the annual variations $\Delta$ of the productions $N_{w}$ and $N_{n w}$ :

$$
\Delta|E|=\left|f_{w}\right| \Delta N_{w}+\left|f_{n w}\right| \Delta N_{n w}
$$


If we impose $\Delta N_{n w}=-\Delta N_{w}$, there is effectively substitution of the wood products for the competing non-wood products. The displacement factor (before normalisation to the carbon mass in the wood products) is, in this case:

$$
D F=-\Delta|E| / \Delta N_{w}=\left|f_{n w}\right|-\left|f_{w}\right|
$$

This factor is negative (increase in emission) or positive (reduction in emission) depending on whether $\left|f_{w}\right|>\left|f_{n w}\right|$ or $\left|f_{w}\right|<\left|f_{n w}\right|$.

Thus, the substitution coefficients cannot apply to productions (or consumptions) but only to their variations. It should also be specified that the "eligible" products are those which are effectively substitutable for other non-wood products (paper, for example, has no real "non-wood" equivalent: a substitution credit or debit should not be attributed to its production).

Some authors [e.g. 48, 50] who are aware of these conditions, restrict the application of displacement factors defined by eq. (4) to increases in production of eligible wood products, compared to a reference year (marginal production). This restriction is necessary but it is not sufficient.

A critical example, inspired by publications by Déry [26] and Bird [28], is provided by the graphical representations in fig. 5 . The production (or consumption) $N_{w}$ of wood products is growing linearly in time (red line), while that $N_{n w}$ of competing products is symmetrically decreasing (green line). The total production remains constant, $\Delta N_{n w}=-\Delta N_{w}$ : there is effective substitution. Thus, according to eq. (3):

$$
\Delta|E|=\left(\left|f_{w}\right|-\left|f_{n w}\right|\right) \Delta N_{w}
$$

In this case, the direct application of the displacement factor (4) to the variation $\Delta N_{w}$ is valid. However, let us suppose that the production of the alternative product also increases linearly (purple line) in response to a market demand, independently of that of the wood product. Then, the change in emission would just be: 


$$
\Delta|E|=\left|f_{w}\right| \Delta N_{w}+\left|f_{n w}\right| \Delta N_{n w}
$$

This variation in emission cannot be attributed to one product rather than the other. Each of them has its share, $\left|f_{w}\right| \Delta N_{w}$ for the wood product, $\left|f_{n w}\right| \Delta N_{n w}$ for the competing product. There is no substitution but simply variation of the volumes produced and market shares. It would not be justified to attribute a credit or debit of emissions to one or the other of the productions.

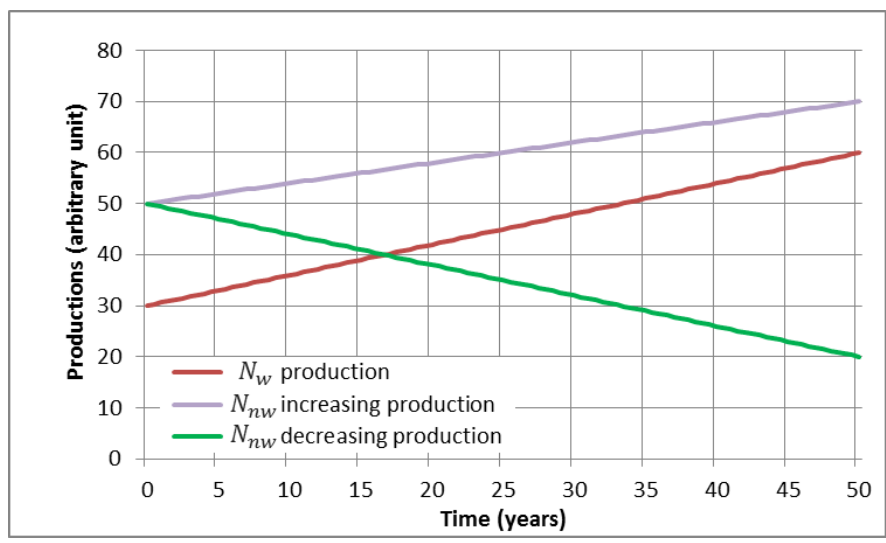

Fig. 5. Examples of effective substitution (red line - green line)

and simple variation of productions (red line - purple line)

A generalisation is possible in the following way. If the total production variation $\Delta N$ is fixed a priori:

$$
\Delta\left(N_{w}+N_{n w}\right)=\Delta N
$$

the variations of $N_{w}$ and $N_{n w}$ are then linked by $\Delta N_{n w}=\Delta N-\Delta N_{w}$. Consequently:

$$
\Delta|E|=\left(\left|f_{w}\right|-\left|f_{n w}\right|\right) \Delta N_{w}+\left|f_{n w}\right| \Delta N
$$


and the displacement factor to be applied is:

$$
D F=-\Delta|E| / \Delta N_{w}=\left|f_{n w}\right|-\left|f_{w}\right|-\left|f_{n w}\right| \Delta N / \Delta N_{w}
$$

expression which covers eq. (4) for $\Delta N=0$.

If there is no constraint on the variation of the total production, there is no reason to attribute substitution credits or debits.

\section{Conclusions}

The substitution of wood for other fuels or other materials, which some believe to be more efficient in limiting the greenhouse effect than carbon capture and its direct storage in live trees, may be in reality counterproductive or, to say the least, its effects are greatly overestimated.

Energy substitution is a very bad idea since the emission factor of wood is higher than that of any other fuel. The time required for the regeneration of exploited stands (time to sequestration parity), beyond which a GHG benefit may be expected, cannot hide this inescapable physical reality. The time horizons set for the achievement of greenhouse gas emission reduction objectives (30 to 80 years) are, in most cases, less than this time to sequestration parity. It would therefore be appropriate to reduce the consumption of wood energy by the inverse substitution of less carbon intensive fuels or, better still, non-carbonaceous sources of energy.

Regarding material substitution, constant displacement factors put forward to promote it are overestimated, up to 2 to $4 \mathrm{tC}$ per ton of carbon for lumber products, for example, when referring to a near future. It is still possible to find favourable substitutions, particularly in the construction sector, but the total of the emission reductions can only be marginal, given that only effective substitutions can be taken into account. 
The current option to increase forest harvesting with a view to climate change mitigation through substitution effects is therefore a serious error. This does not mean that the utilisation of wood produced by forests is not legitimate, but only that this utilisation cannot be justified by reasons of mitigation of climate change, except in very special cases. Forest exploitation and wood use should simply respond to technical, economic, social or societal needs while being subject, like other activities, to a precise carbon accounting that allows judging, case by case, if it is well-founded (asserting "zero" for biomass emission factor is not an accounting practice).

Alternatively, to enable the forest to play an important and perhaps decisive role in mitigating climate change, the direct means of increasing wooded areas and standing tree volumes remain, therefore storing carbon in the forests and, conditionally, in wood products. To be effective, this strategy must rely on reforestation and restoration of natural forests more than on the plantation of forests with productive objectives $[52,53]$.

\section{Abbreviations}

GHG: Greenhouse gas; DF: Displacement factor; HWP: Harvested wood product; NPP: Net primary production; GWP: Global warming potential

\section{Declarations}

\section{Ethics approval and consent to participate}

Not applicable

\section{Consent for publication}

Not applicable 


\section{Availability of data and materials}

Not applicable

\section{Competing interest}

The author declare that he has no competing interest

\section{Funding}

No funding

\section{Author's contribution}

Philippe Leturcq is the author of the research and the manuscript

\section{Acknowledgments}

The author is indebted to Henri Dedieu, Elodie Roulier and Gilles Tierle for helpful comments and to Sophie Chambers for her editorial assistance.

\section{Author's information}

Philippe Leturcq is a retired University Professor (University of Toulouse, National Institute for Applied Sciences and Laboratory for Analysis and Architecture of Systems, CNRS). Address: Tuc de Grand, 09230 Bédeille, France; e-mail: phleturcq@hotmail.fr

\section{References}

1. Hall DO, Mynick HE, Williams RH. Cooling the greenhouse with bioenergy. Nature. 1991;353:11-12

2. Schlamadinger B, Marland G. The role of forest and bioenergy strategies in the global carbon cycle. Biomass and Bioenergy. 1996;10:275-300. 
3. Pingoud K, Perala AL, Soimakallio S, Pussinen A. Greenhouse gas impacts of harvested wood products. Evaluation and development of methods. Espoo 2003. VTT Tiedotteita. Research Notes 2189.

4. Sathre R, Gustavsson L. A state-of-the-art review of energy and climate effects of wood product substitution. School of Technology and Design Reports, No. 57, Växjö University. 2009.

5. Bergman R, Puettmann M, Taylor A, Skog KE. The Carbon Impacts of Wood Products. Forest Products Journal. 2014;64:220-31.

6. Baul TK, Alam A, Strandman H, Kilpeläinen A. Net climate impacts and economic profitability of forest biomass production and utilization in fossil fuel and fossil-based material substitution under alternative forest management. Biomass and Bioenergy. 2017;98:291-305.

7. Gustavsson L, Haus S, Lundblad M, Lundström A, Oritz CA, Sathre R, Le Troung N, Wikberg PE. Climate change effects of forestry and substitution of carbon-intensive materials and fossil fuels. Renew. Sustain. Energy Rev. 2017;67:612-24.

8. Bösch M, Elsasser P, Rock J, Weimar H, Dieter M. Extent and costs of forest-based climate change mitigation in Germany: accounting for substitution. Carbon Management. 2019. DOI:10.1080/17583004.2018.1560194.

9. McKechnie J, Colombo S, Chen J, Mabee W, MacLean HL. Forest Bioenergy or Forest Carbon ? Assessing Trade-Offs in Greenhouse Gas Mitigation with Wood-Based Fuels. Environ. Sci. Technol. 2011;45:789-95.

10. Mitchell SR, Mark EH, O'Connell KEB. Carbon debt and carbon sequestration parity in forest bioenergy production. GCB Bioenergy. 2012. doi: 10.1111/j.1757-1707.2012.01173.x.

11. Ter-Michaelian MT, Colombo SJ, Lovekin D, McKechnie J, Reynolds R, Titus B, Laurin E, Chapman AM, Chen J, Maclean HL. Carbon debt repayment or carbon sequestration parity? Lessons from a forest bioenergy case study in Ontario, Canada. GCB Bioenergy. 2015;7:70416. doi: $10.1111 /$ gcbb.12198.

12. Leskinen P, Cardellini G, González-García S, Hurmekoski E, Sathre R, Seppälä J, Smyth C, Stern $T$, Verkerk PJ. Substitution effects of wood-based products in climate change mitigation. From Science to Policy 7, European Forest Institute. 2018.

13. Sterman JD, Siegel L, Rooney-Varga JN. Does replacing coal with wood lower $\mathrm{CO} 2$ emissions? Dynamic lifecycle analysis of wood bioenergy. Environ. Res. Lett. 2018;13:015007. https://doi.org/10.1088/1748-9326/aaa512.

14. Norton M, Baldi A, Buda V, Carli B., Cudlin P, Jones MB, Korhola A, Michalski R, Novo F, Oszlányi J, Duarte Santos F, Schink B, Shepherd J, Vet L, Walloe L, Wijkman A. Serious mismatches continue between science and policy in forest bioenergy. GCB Bioenergy. 2019. 2019;00:1-8. DOI:10.1111/gcbb.12643.

15. Winchester N, Reilly JM. The economic and emissions benefits of engineered wood products in a low-carbon future. Energy Economics. 2020.

https://doi.org/10.1016/j.eneco.2019.104596

16. Johnson E. 2009. Goodbye to carbon neutral: getting biomass footprints right. Environ. Impact Assess. Rev. 2009;29:165-8

17. Ter-Mikaelian MT, Colombo SJ, Chen J. The Burning Question: Does Forest Energy Reduce Carbon Emissions ? A Review of Common Misconceptions about Forest Carbon Accounting. Journal of Forestry. 2015;113: 57-68. 
18. Valade A, Luyssaert S, Vallet P, Njakou Djomo S, van der Kellen IJ, Bellassen V. Carbon costs and benefits of France's biomass energy production targets. Carbon Balance and Management. 2018;13:(1), 10.1186/s13021-018-0113-5 . hal-01956112.

19. Roux A, Dhôte JF (Coordinateurs), Achat D, Bastick C, Colin A, Bailly A, Bastien JC, Berthelot A, Bréda N, Caurla S, Carnus JM, Gardiner B, Jactel H, Leban JM, Lobianco A, Loustau D, Meredieu C, Marçais B, Martel S, Moisy C, Pâques L, Picart-Deshors D, Rigolot E, Saint-André L, Schmitt B. Quel rôle pour les forêts et la filière forêt-bois françaises dans l'atténuation du changement climatique? Une étude des freins et leviers forestiers à l'horizon 2050. Rapport d'étude pour le Ministère de l'agriculture et de l'alimentation, INRA et IGN. 2017.

20. Smyth C, Rampley G, Lemprière TC, Schwab O, Kurz WA. Estimating product and energy substitution benefits in national-scale mitigation analyses of Canada's forest sector. GCB Bioenergy. 2017;9:1071-84.

21. Chen J, Ter-Mikaelian MT, Yang H, Colombo SJ. 2018. Assessing the greenhouse gas effects of harvested wood products manufactured from managed forests in Canada. Forestry. 2018;91:193-205.

22. Seppäläa J, Heinonen T, Pukkala T, Kilpeläinen A, Mattila T, Myllyviita T, Asikainen A, Peltola $H$. Effect of increased wood harvesting and utilization on required greenhouse gas displacement factors of wood-based products and fuels. Journal of Environmental Management. 2019;247:580-7.

23. Holmgren $\mathrm{P}$, Kolar K. Reporting the overall climate impact of a forestry corporation - the case of SCA. 2019. https://mb.cision.com/Main/600/2752801/999695.pdf. Accessed 12 Dec 2019.

24. Geng A, Chen J, Yang H. Assessing the Greenhouse Gas Mitigation Potential of Harvested Wood Products Substitution in China. Environ. Sci. Technol. 2019;53:1732-40.

25. Sathre R, O'Connor J. Meta-analysis of greenhouse gas displacement factors of wood product substitution. Environmental Science \& Policy. 2010;13:104-14.

26. Déry P. Substitution énergétique : Mythe ou réalité ?. Rapport sur l'énergétique régionale du Saguenay-Lac-St-Jean, Québec, Canada; 2007.

27. York R. Do alternative energy sources displace fossil fuels ? Nature Climate Change. 2012;2:441-3

28. Bird DN. Estimating the displacement of energy and materials by woody biomass in Austria. Joanneum Research resources, deliverable N.06; 2013.

29. Searchinger TD, Hamburg SP, Melillo J, Chameides W, Havlik P, Kammen DM, Likens GE, Lubowski RN, Obersteiner M, Oppenheimer M, Robertson GP, Schlesinger WH, Tilman GD. Fixing a critical climate accounting error. Science 2009;326:527-8.

30. Leturcq Ph. La neutralité carbone du bois énergie : un concept trompeur. Rev For Fr (Nancy). 2011;LVIII:723-34

31. Haberl H, Sprinz D, Bonazountas $M$, Cocco $P$, Desaubies $Y$, Henze $M$, Ole $H$, Johnson RK, Kastrup U, Laconte P, Lange E, Novak P, Paavola J, Reenberg A, van den Hove S, Vermeire T, Wadhams $P$, Searchinger T. Correcting a fundamental error in greenhouse gas accounting related to bioenergy. Energ. Pol. 2012;45:18-23

32. Brack D. Woody biomass for Power and Heat - Impacts on the Global Climate. The Royal Institute of International Affairs, Chatham House, London; 2017.

33. Searchinger TD, Beringer T, Holtsmark B, Kammen DM, Lambin EF, Lucht W, Raven P, van Ypersele JP. Europe's renewable energy directive poised to harm global forests. Nature communications.2018;9:3741. DOI: 10.1038/s41467-018-06175-4. 
34. Skovsgaard JP, Vanclay JK. Forest site productivity: a review of the evolution of dendrometric concepts for even-aged stands. Forestry. 2008;81:13-31.

35. 2006 IPCC Guidelines for National Greenhouse Gas Inventories. Edited by Eggleston HS, Buendia L, Miwa K, Ngara T and Tanabe K. Published: IGES, Japan. Volume 2: Energy, Chapter 2: Stationary combustion.

36. Koffi B, Cerutti A, Duerr M, lancu A, Kona A, Janssens-Maenhout G. CoM Default Emission Factors for the Member States of the European Union. European Commission, Joint Research Centre (JRC). 2017. http://data.europa.eu/89h/jrc-com-ef-comw-ef-2017. Accessed 6 Fev 2020.

37. Lamers $P$, Junginger $M$. The ' $\mathrm{debt}^{\prime}$ ' is in the detail: $\mathrm{A}$ synthesis of recent temporal forest carbon analyses on woody biomass for energy. Biofuels, Bioprod. Bioref. 2013;7:373-85.

38. Agostini A, Giuntoli J, Boulamanti A. Carbon accounting of forest bioenergy, conclusions and recommendations from a critical literature review. JRC scientific and policy report EUR 25354 EN edited by: Luisa Marelli. 2014.

39. Geng A, Yang H, Chen J, Hong Y. Review of carbon storage function of harvested wood products and the potential of wood substitution in greenhouse gas mitigation. Forest Policy and Economics. 2017;85:192-200.

40. Leturcq Ph. Wood preservation (carbon sequestration) or wood burning (fossil-fuel substitution), which is better for mitigating climate change ? Annals of Forest Science. 2014;71:117-24.

41. Soimakallio S, Laura Saikku L, Valsta L, Pingoud K. Climate Change Mitigation Challenge for Wood Utilization - The Case of Finland. Environ. Sci. Technol. 2016;50:5127-34.

42. Knauf M, Köhl M, Mues V, Olschofsky K, Frühwald A. 2015. Modeling the CO2-effects of forest management and wood usage on a regional basis. Carbon Balance and Management. 2015;10:13. DOI 10.1186/s13021-015-0024-7

43. Heinonen T, Pukkala T, Mehtätalo L, Asikainen A, Kangas J, Peltola H. Scenario analyses for the effects of harvesting intensity on development of forest resources, timber supply, carbon balance and biodiversity of Finnish forestry. Forest Policy and Economics. 2017;80:80-98.

44. Law BE, Hudiburg TW, Berner LT, Jeffrey J, Kent JJ, Buotte PC, Harmon ME. Land use strategies to mitigate climate change in carbon dense temperate forests. PNAS. 2018;115:3663-8.

45. Harmon ME. Have product substitution carbon benefits been overestimated? A sensitivity analysis of key assumptions. Environ. Res. Lett. 2019;14:065008

46. Pingoud K, Pohjola J, Valsta L. Assessing the integrated climatic impacts of forestry and wood products. Silva Fennica. 2010;44:155-75.

47. Oliver CD, Nassar NT, Lippke BR, McCarter JB. Carbon, Fossil Fuel, and Biodiversity Mitigation With Wood and Forests. Journal of Sustainable Forestry. 2014;33:248-75.

48. Smyth CE, Stinson G, Neilson E, Lemprière TC, Hafer M, Rampley G, Kurz WA. Quantifying the biophysical climate change mitigation potential of Canada's forest sector. Biogeosciences. 2014;11:3515-29.

49. Deheza M, N'Goran C, Bellassen V. L'atténuation du changement climatique par les produits bois au sein des politiques françaises : priorité au bois énergie. Étude Climat, $n^{\circ} 47, C D C$ Climat Recherche; 2014. 
50. Valade A, Bellassen V, Magand C, Luyssaert S. Sustaining the sequestration efficiency of the European forest sector. Forest Ecology and Management. 2017;405:44-55. 10.1016/j.foreco.2017.09.009. hal-01675305.

51. Sathre R, O'Connor J. A Synthesis of Research on Wood Products and Greenhouse Gas Impacts. $2^{\text {nd }}$ Edition, Vancouver B.C., FPInnovations, Technical Report TR-19R. 2010.

52. Moomaw WR, Masino SA, Faison EK. Intact Forests in the United States: Proforestation Mitigates Climate Change and Serves the Greatest Good. Front. For. Glob. Change 2019 ;2:27. doi: 10.3389/ffgc.2019.00027.

53. Lewis SL, Wheeler CE, Mitchard ETA, Koch A. Restoring natural forests is the best way to remove atmospheric carbon. Nature 2019;568:25-28. 
Figures

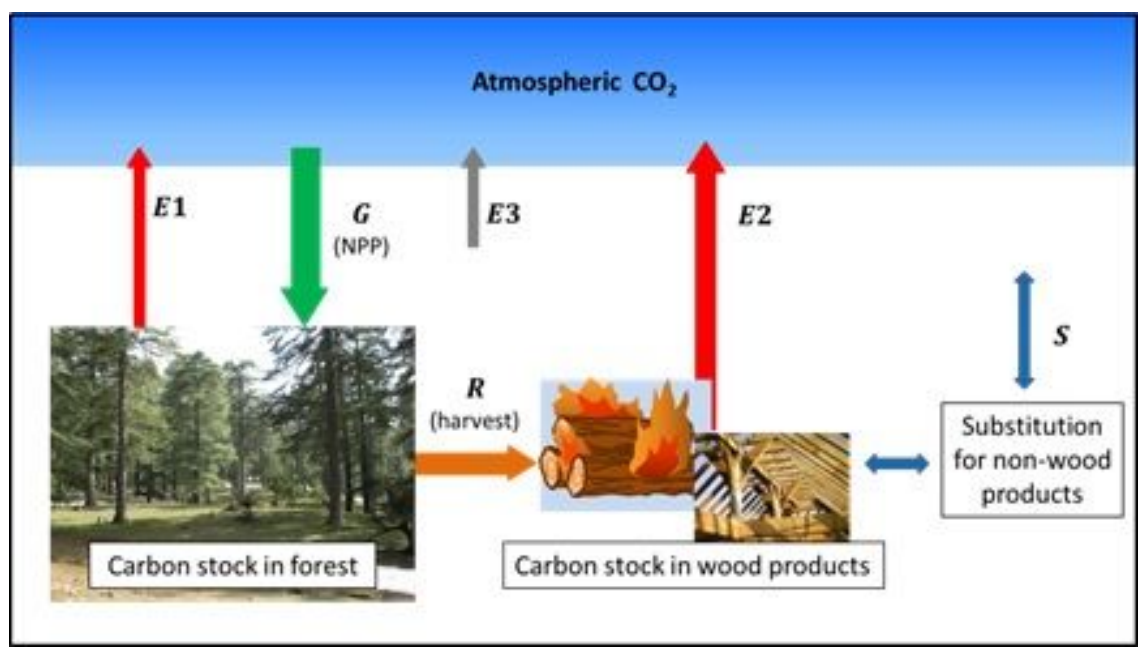

\section{Figure 1}

Carbon flux exchanges between forest, wood products and atmosphere (G: Net primary production; E1: decomposition of dead organic matter; R: harvested wood; E2: combustion or decomposition of harvested wood; E3: external emissions; S: substitution effect)

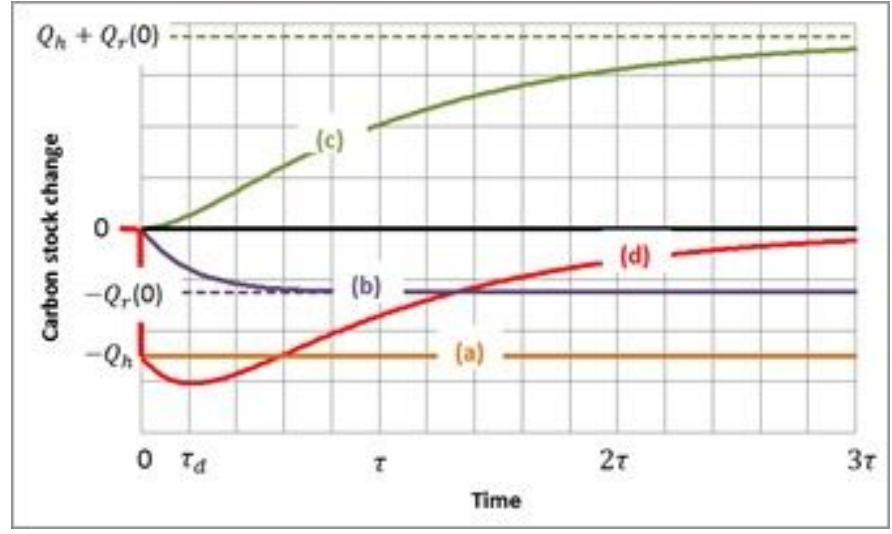

\section{Figure 2}

Main components of the forest carbon stock change (d) due to harvesting (a): carbon content of the harvested wood (b): decomposition of harvest residues (c): forest regeneration 


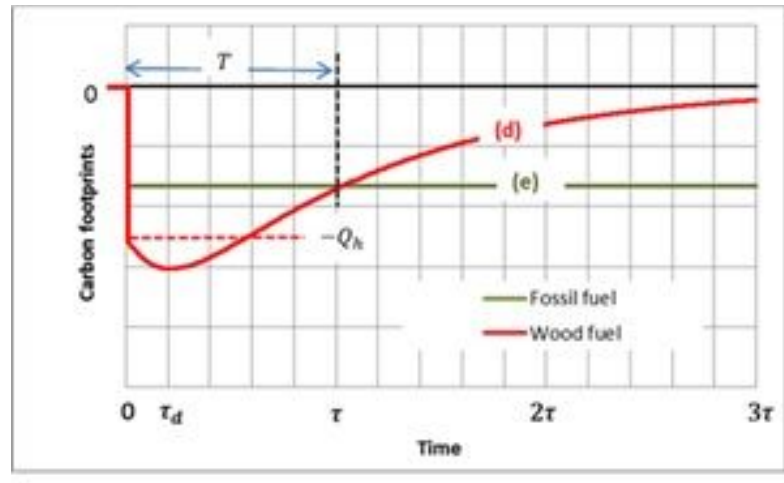

(a) Intrinsic carbon footprints

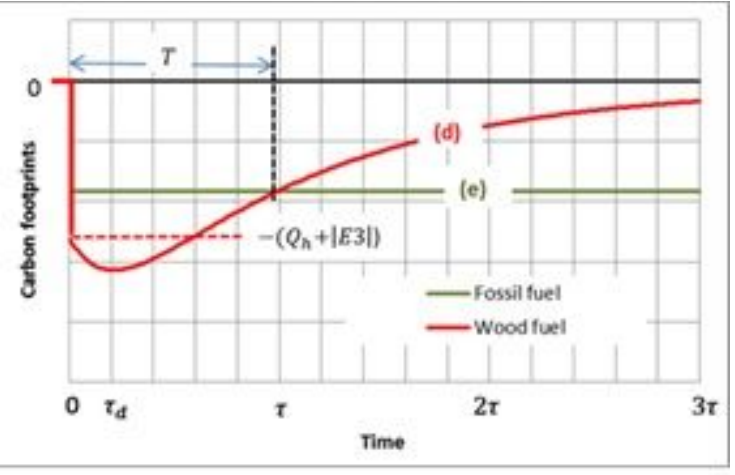

(b) Extrinsic emissions taken into account

\section{Figure 3}

Comparison of the carbon footprints of wood and fossil fuels for the same energy released

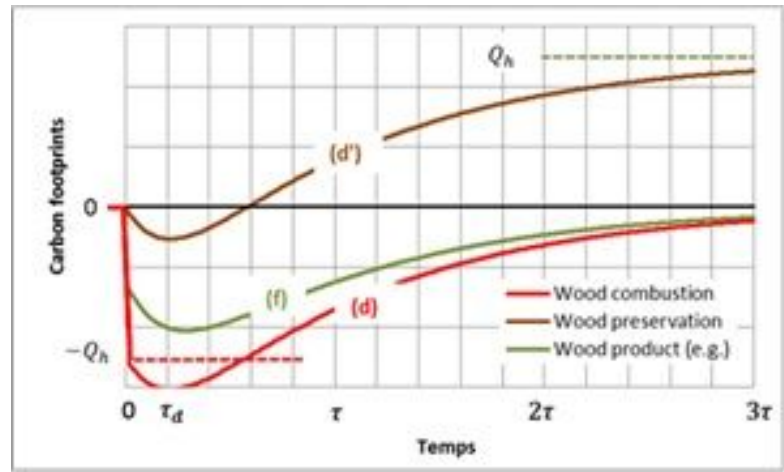

(a)

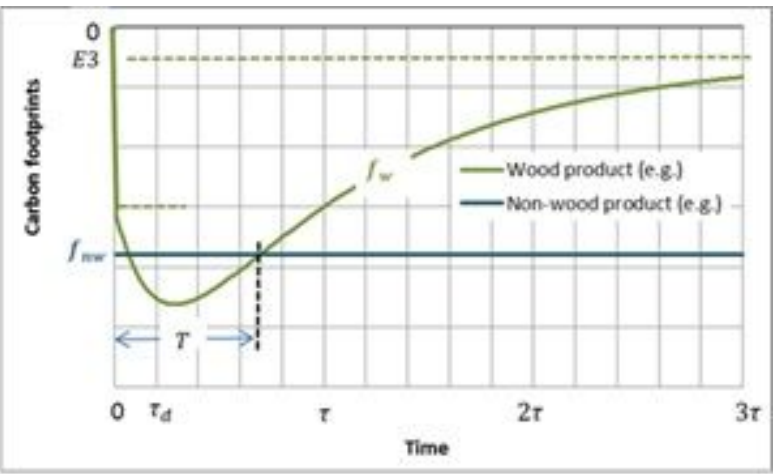

(b)

\section{Figure 4}

Example of a carbon footprint of a wood product (a) and definition of the time to sequestration parity in the substitution for a non-wood product (b) The vertical scale unit in fig. $4 \mathrm{~b}$ is divided in two for clarity in comparison to that in fig. $4 a$

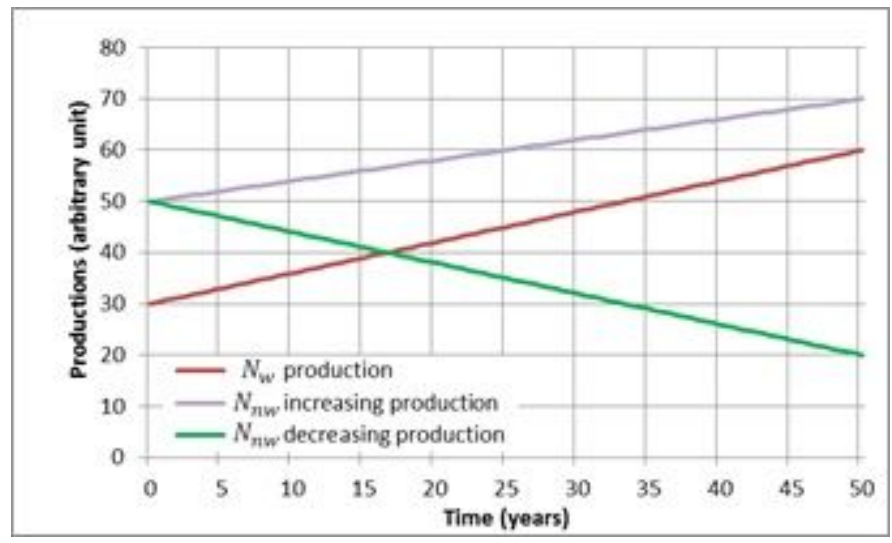

Figure 5 
Examples of effective substitution (red line - green line) and simple variation of productions (red line purple line) 